\title{
Risk of Adverse Outcomes for Older People with Dementia Prescribed Antipsychotic Medication: A Population Based e-Cohort Study
}

\author{
Michael Dennis (D) Laura Shine · Ann John · Amanda Marchant • \\ Joanna McGregor $\cdot$ Ronan A. Lyons · Sinead Brophy
}

Received: October 20, 2016/ Published online: January 4, 2017

(C) The Author(s) 2017. This article is published with open access at Springerlink.com

\begin{abstract}
Introduction: Over recent years there has been growing evidence of increased risk of mortality associated with antipsychotic use in older people with dementia. Although this concern combined with limited evidence of efficacy has informed guidelines restricting antipsychotic prescription in this population, the use of antipsycotics remains common. Many published studies only report short-term outcomes, are restricted to examining mortality and stroke risk or have other limitations. The aim of this study was to assess
\end{abstract}

Enhanced Content To view enhanced content for this article go to http://www.medengine.com/Redeem/ 3B47F0602190EE22.

Electronic supplementary material The online version of this article (doi:10.1007/s40120-016-0060-6) contains supplementary material, which is available to authorized users.

M. Dennis $(\varangle) \cdot$ A. John · A. Marchant .

J. McGregor · R. A. Lyons · S. Brophy

Farr Institute of Health Informatics Research,

Swansea University Medical School, Swansea, Wales,

UK

e-mail: m.s.dennis@swansea.ac.uk

L. Shine

Cwm Taf Health Board, Port Talbot, Wales, UK adverse outcomes associated with the use of antipsychotics in older people living with dementia in Wales (UK).

Methods: This was a retrospective study of a population-based dementia cohort using the Welsh Secure Anonymised Information Linkage databank. The prior event rate ratio (PERR) was used to estimate the influence of exposure to antipsychotic medication on acute cardiac events, venous thromboembolism, stroke and hip fracture, and adjusted Cox proportional hazard models were used to compare all-cause mortality.

Results: A total of 10,339 people aged $\geq 65$ years were identified with newly diagnosed dementia. After excluding those who did not meet the inclusion criteria, 9674 people remained in the main cohort of whom 3735 were exposed to antipsychotic medication. An increased risk of a venous thromboembolic episode [PERR 1.95, 95\% confidence interval (CI) 1.83-2.0], stroke (PERR 1.41, 95\% CI 1.4-1.46) and hip fracture (PERR 1.62, 95\% CI 1.59-1.65) was associated with antipsychotic use. However, there was no long-term increased mortality in people exposed to antipsychotics (adjusted hazard ratio 1.06, 95\% CI 0.99-1.13). 
Conclusions: The increase in adverse medical events supports guidelines restricting antipsychotic use in this population.

Keywords: Antipsychotic medication; Dementia; Mortality; Older people

\section{INTRODUCTION}

There are currently approximately 700,000 people in the UK with dementia [1]. As well as cognitive disturbances, people living with dementia also commonly develop behavioural and psychological symptoms (BPSD). Clinical guidelines for BPSD emphasise managing aetiological factors, and the use of behavioural and psychological interventions [2]. However, antipsychotic medications have often been prescribed for BPSD despite evidence of limited clinical improvement [3-8]. Over the past decade concerns have been raised over the prescribing of antipsychotics in people living with dementia, with the UK Committee for the Safety of Medicines (CSM) and the U.S. Food and Drug Administration (FDA) issuing statements to this effect in 2004 [9] and 2005 [10], respectively. These concerns are supported by meta-analyses of randomised controlled trials (RCTs) $[5,7,11]$ and a large U.S. cohort study [12]. Reports and guidelines for clinicians have subsequently expressed the need for extreme caution in prescribing antipsychotic medication to people living with dementia $[1,2,13,14]$. Despite this, antipsychotics are still commonly used in clinical practice in the UK in this patient group $[15,16]$. The newer, 'atypical' antipsychotic drugs appear to carry lower risk than conventional (typical) antipsychotic agents and the highest risk is in the first 1-3 months of treatment [17-19].

There are, however, issues concerning the findings of increased risk of mortality and other adverse health outcomes in people with dementia prescribed antipsychotic medication. Many of the published studies only report short-term adverse outcomes, the trials are often from highly selected populations, control group selection in observational studies is often inadequate and increased mortality is not a universal finding [20-23].

The objective of our study was to perform a large population-based retrospective electronic-cohort study of older people living with dementia using linked routine data, examining the relationship between antipsychotics and serious adverse outcomes.

\section{METHOD}

\section{Data Source}

The retrospective cohort of older people with dementia for this study was drawn from the Secure Anonymised Information Linkage (SAIL) databank based at the Health Information Research Unit (HIRU), Swansea University. SAIL brings together and links the widest possible range of anonymised routinely collected person-based data held in health and social care datasets in Wales (UK). A large amount of preliminary work on anonymisation methodologies to protect privacy was undertaken to create the SAIL system [24, 25]. SAIL uses a split-file approach to anonymisation to overcome confidentiality and disclosure issues. Within each routine dataset held in the SAIL databank, anonymised individuals are assigned a unique linking field or ALF (Anonymised Linking Field). These are generated by the NHS Wales Information Service using the Matching Algorithm for Consistent Results in Anonymised Linkage with 99.85\% accuracy 
[25]. ALFs are further encrypted within SAIL and used to link de-identified individuals across multiple datasets. The SAIL system represents a valuable resource for health-related research whilst complying with the requirements of data protection legislation and confidentiality guidelines. For a more detailed description of SAIL see Jones et al. [26].

The particular datasets within the SAIL databank utilised for this project were:

- National Health Service

Administrative Register, which is a register of all individuals registered with a Welsh general practitioner (GP) or who have ever had contact with the NHS;

- General Practice Primary Care attendance and clinical information database for all general practice interactions including symptoms, investigations, diagnoses including co-morbidities, prescribed medication and referrals to secondary and tertiary care. The GPD database covered approximately $40 \%$ of the population of Wales at the time of the study;

- Cause of death (Office of National Statistics Public Health Mortality files);

- Patient Episode Dataset for Wales (PEDW), which includes demographic and clinical data on all inpatient and day-case admissions in NHS Wales hospitals and all Welsh residents treated in other UK countries;

- Outpatient Dataset, a minimum dataset listing all outpatient appointments, including mental health services in NHS Wales hospitals.

\section{Study Cohort}

The SAIL databank was interrogated using structured query language (DB2 SQL) to create a cohort of people registered to a SAIL supplying
GP practice and aged $\geq 57$ years at the onset of the study period (1 January 2003). From this group, those with a new diagnosis of dementia during the study period (1 January 2003 to 31 December 2011) and aged $\geq 65$ years at diagnosis were identified. The diagnosis of dementia was taken from GP computer records using NHS Read browser terminology. Read codes are a coded thesaurus of clinical terms which have been used in the NHS since 1985 and are still widely used in the primary care sector. They are the standard clinical terminology by which clinicians can record patient findings and procedures. The Read codes used to identify participants for the cohort were determined by using READ Version 2 (5-byte). This database was manually reviewed and searched by the researchers to identify all the possible codes that may have been used to record a diagnosis of dementia (Appendix). To ensure the list of codes was complete as possible, we also checked our list against codes for dementia used to identify cases for the Quality and Outcomes Framework (QOF READ codes v27 for 2013/2014 [27]) and the updated Charlson Index [28]. Patients entered the cohort at the date of diagnosis of dementia and left on the date of death, date of leaving a SAIL supplying a GP or the study end, whichever was the sooner.

Exclusions from the cohort included people who had a prior diagnosis of schizophrenia and bipolar affective disorder (functional psychosis) and individuals diagnosed with cancer within one year date of death. These individuals were again identified in a similar manner from the GP Read Coding [Electronic Supplementary Material (ESM) Tables S1-3]. The exclusion of people with functional psychosis was due to the fact that the antipsychotic prescription was likely to be for the treatment of the underlying psychotic illness, and the exclusion 
of cancer patients was because antipsychotics are used commonly for a different clinical indication, namely nausea in the context of palliative care.

\section{Exposure to Antipsychotic and Other Psychotropic Medications}

From linked and anonymised prescribing records we then determined whether participants in the cohort had received antipsychotic medication. From the GP database we collated all prescriptions of antipsychotic medications, again determined by NHS Read codes (ESM Table S20). The type of medication was further divided into conventional (typical) and newer atypical antipsychotics. Because of the debate concerning the status of sulpiride (historically conventional but structurally related to newer drugs), this drug was coded separately to allow inclusion in either group. We also recorded information on the prescription of other psychotropic medications, in particular hypnotics and anxiolytics (ESM Tables S21 and S22). Within these groups data on benzodiazepine prescriptions were reviewed (ESM Table S23).

With regard to the prescriptions the date of first prescription after dementia diagnosis was recorded.

We divided the cohort into two groups: one who had received a prescription for antipsychotic medications and a comparison who had not (Fig. 1).

\section{Clinical Characteristics, Co-morbidity and Outcomes}

Data evaluated on all participants included in the cohort were gender and age at diagnosis of dementia. The following co-variants were also determined from the database information: cerebrovascular disease, ischaemic heart disease, parkinsonism, hip fracture, venous thromboembolic event, atrial fibrillation, epilepsy and diabetes. These co-variants were identified using NHS Read codes (ESM Tables S4-11) and their occurrence or non-occurrence prior to the onset of dementia was recorded.

The primary outcome was a serious adverse event, including death, cerebrovascular disease (episode of stroke or transient ischaemic attack), acute cardiac event, venous thromboembolic events [deep vein thrombosis (DVT) or pulmonary embolism (PE)] and hip fracture.

Participants were followed for the duration of the study, their time in the cohort, and length of follow-up dependent on their date of diagnosis of dementia. The outcomes were determined by using anonymously linked information on each participant in the cohort. Adverse outcomes were recorded from GP data based on NHS Read codes (ESM Supplementary Tables S12, S14, S16, S18). This information was combined with data from PEDW; diagnosis in our study was based on ICD-10 codes (ESM Supplementary Tables S13, S15, S17, S19). Data on death was obtained from the Office of National Statistics database and included information on date and cause of death. The Read and ICD10 codes were selected by manually searching the relevant classification lists. To ensure completeness of the included Read codes and ICD-10 we again checked our list against updated Charlson Index codes [28, 29].

\section{Statistical Analysis}

Basic demographic characteristics and history of medical co-morbidities were compared between 


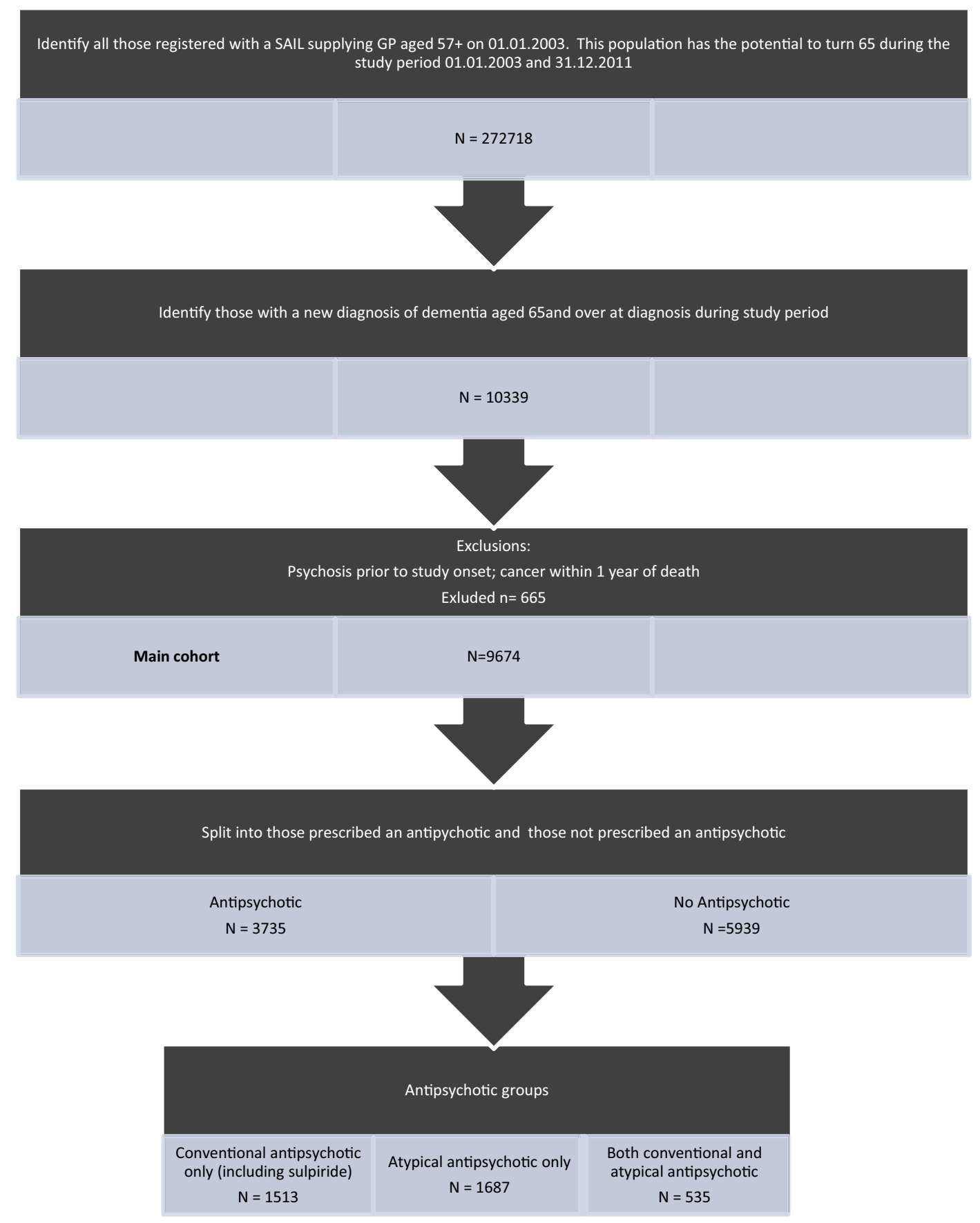

Fig. 1 Assembly of study cohort of older people with dementia. SAIL Secure Anonymised Information Linkage database

people with and without exposure to diagnosis (epilepsy, parkinsonism, atrial antipsychotic medication. Adjusted relative fibrillation, history of thromboembolism, risks of death were calculated with Cox's diabetes, ischaemic heart disease, proportional hazard models. Risk was adjusted cerebrovascular disease, and previous hip for age, gender and co-morbidities at dementia fracture; Model 1). Further adjustment was 
made for use of hypnotics, anxiolytics and benzodiazepines (Model 2).

The prior event rate ratio (PERR) adjustment method was used to estimate the effects of exposure to antipsychotic medication on the likelihood of experiencing the adverse medical outcomes of acute cardiac event, venous thromboembolism, stroke and hip fracture. The time to first event over 12 months of follow-up (incidence) was calculated from the date of the first antipsychotic (follow-up for 12 months) and for the 12-month period prior to the date of the first antipsychotic. For those not given an antipsychotic, a random date was chosen to calculate time to first event prior and post this random date. The PERR is calculated as:

$$
\text { PERR }=\frac{\text { Rate ratio during post period }}{\text { Rate ratio during prior period }} .
$$

Confidence intervals (CIs) were obtained by bootstrapping. The method assumes that the confounding effects are constant across the prior and post exposure periods and that there is no confounder by treatment interactions $[30,31]$. The PERR cannot be applied for terminal events and so was used to examine acute cardiac events, venous thromboembolism (DVT and PE), stroke and hip fracture-but not mortality.

All data were analysed using STATA version 12 [32].

\section{Secondary Analyses}

To explore whether particular types of dementia had different risk profiles we performed a sub-group analysis examining outcomes for people suffering from the main type of dementia, Alzheimer's disease (AD). Secondary analyses also included a comparison of outcomes in people receiving newer atypical antipsychotics and those receiving conventional antipsychotic medication. Adjusted hazard ratios (HRs) were calculated for both models. Additionally, we examined mortality rates in 100-day blocks following initial antipsychotic prescription.

\section{Additional Sensitivity Analyses}

We conducted two additional analyses to further examine mortality risk differences:

1. Excluding people with contact with specialist services in old age psychiatry. This was performed in the case that antipsychotic medication had been prescribed in a secondary care setting that would not have been identified in the primary care database. It is possible that antipsychotic medication could be prescribed by specialist services in an emergency situation or at the commencement of treatment in an out-patient consultation.

2. To determine whether the exclusion of people with a diagnosis of cancer within 1 year of death influenced the results, we repeated the main analysis by including these people.

\section{Compliance with Ethics Guidelines}

This article does not contain any new studies with human or animal subjects performed by any of the authors. Ethical approval was granted from the HIRU Information Governance Review Panel, an independent body consisting of a range of government, regulatory and professional agencies which oversees study approvals in line with permissions already granted to the analysis of data in the SAIL databank [24, 25]. 
The results are reported in accordance with the STROBE checklist (http://www.epidem. $\mathrm{com} /)$.

\section{RESULTS}

\section{Cohort Characteristics}

From 2003 until 2011 there were 272,718 people registered with a SAIL supplying GP in Wales who were or had the potential to turn 65 years of age during the study period. From these we identified 10,339 people with a new diagnosis of dementia aged $\geq 65$ years at diagnosis. A total of 665 were excluded because of pre-existing functional psychosis or a diagnosis of cancer within 1 year of death, leaving a total of 9674 people with dementia forming the main cohort. Within this main cohort, 3735 were exposed to antipsychotic medication, and 5939 did not receive any antipsychotics from their GP following their dementia diagnosis. Figure 1 provides a summary of the dementia e-cohort assembly process.

The demographic characteristics and baseline medical co-morbidities of older people with dementia exposed and not exposed to antipsychotic medications were remarkably similar (Table 1 ). The exceptions to this were a small difference in gender, with males more likely to receive antipsychotics, and a higher proportion of people in the non-exposed group suffering from diabetes before dementia diagnosis. There were high rates of baseline co-morbidity, particularly ischaemic heart disease and cerebrovascular disease. The median follow-up period (until death, leaving a SAIL supplying GP, or end of study period) was 1.8 [interquartile range (IQR) 0.8-3.3] years in the main dementia cohort, 2.2
(IQR 1.1-3.8) years in the group exposed to antipsychotic medication and 1.5 (IQR 0.6-3.0) years in those not exposed to antipsychotics.

\section{Antipsychotic Exposure, Mortality and Other Main Outcomes}

Older people with dementia exposed to antipsychotic medication did not have an increased risk of mortality compared to non-exposed people when adjustment was made for age at dementia diagnosis, gender or baseline co-morbidity (Model 1) or after adjusting for age at dementia diagnosis, gender, baseline co-morbidity and exposure to anxiolytic and/or hypnotic medication (Model 2) (Table 2). However, PERR analysis showed a greater likelihood of increased venous thromboembolism (DVT and PE), stroke and hip fracture, but not acute cardiac event, in those receiving antipsychotic medication (Table 3).

\section{Secondary Analyses}

There were 6996 people with a diagnosis of Alzheimer-type dementia, representing $72 \%$ of those within the main dementia cohort. Vascular dementia was the other main dementia subtype $(n=2333 ; 24 \%)$, followed by Lewy Body dementia $(n=139,1.4 \%)$ and mixed dementia $(n=132,1.4 \%)$. There were no significant differences in the proportions of people in different dementia subtype groups receiving antipsychotic medication (Chi-square 2.66(4), two-tailed $P=0.62$ ). In both models of adjustment, people with $\mathrm{AD}$ exposed to antipsychotic drugs had no higher mortality risk than non-exposed individuals (Table 2). However, PERR analysis showed a greater likelihood of acute cardiac event, venous thromboembolism, stroke and hip fracture in 
Table 1 General characteristics of dementia cohort by antipsychotic use

\begin{tabular}{|c|c|c|c|}
\hline $\begin{array}{l}\text { General characteristics of } \\
\text { study cohort }\end{array}$ & $\begin{array}{l}\text { Exposed to antipsychotic } \\
\text { medication }(n=3735)\end{array}$ & $\begin{array}{l}\text { Not exposed to antipsychotic } \\
\text { medication }(n=5939)\end{array}$ & $\begin{array}{l}\text { \% Difference } \\
(95 \% \mathrm{CI})\end{array}$ \\
\hline Female & $66.2 \%(2474)$ & $67.8 \%(4025)$ & $1.5^{*}(0-3.4)$ \\
\hline $\begin{array}{l}\text { Mean age at diagnosis of } \\
\text { dementia (years) }\end{array}$ & $82.4(6.8)$ & $82.5(6.8)$ & $0.1(-0.1$ to 0.4$)$ \\
\hline \multicolumn{4}{|l|}{ History of } \\
\hline Epilepsy & $2.7 \%(99)$ & $2.3 \%(138)$ & $0.3(-0.3$ to 1.0$)$ \\
\hline Parkinsonism & $4.0 \%(149)$ & $3.7 \%(222)$ & $0.25(-0.5$ to 1.1$)$ \\
\hline Atrial fibrillation & $14.6 \%(546)$ & $15.4 \%(914)$ & $0.7(-2.2$ to 0.7$)$ \\
\hline $\begin{array}{l}\text { Venous } \\
\text { thromboembolism }\end{array}$ & $5.8 \%(217)$ & $5.5 \%(329)$ & $0.27(-0.6$ to 1.2$)$ \\
\hline Diabetes & $13.7 \%(511)$ & $15.8 \%(941)$ & $2.2^{*}(0.7-3.6)$ \\
\hline Ischaemic heart disease & $23.9 \%(893)$ & $23.2 \%(1377)$ & $0.7(-1.0$ to 2.5$)$ \\
\hline Cerebrovascular disease & $22.3 \%(832)$ & $22.5 \%(1338)$ & $0.25(-2.0$ to 1.5$)$ \\
\hline Hip fracture & $6.5 \%(243)$ & $6.1 \%(364)$ & $0.4(-0.6$ to 1.4$)$ \\
\hline
\end{tabular}

* Significant difference between the group exposed to antipsychotic medication and the group not exposed

Values in table are presented as the percentage with the number (of people) in parenthesis, with the exception of Mean age at diagnosis which is presented as the mean age with the standard deviation in parenthesis

those receiving antipsychotic medication (Table 3).

There were 3735 (39\%) people exposed to antipsychotic medication in the main dementia cohort, of whom 1687 received an atypical antipsychotic medication, 1495 receive a conventional antipsychotic drug, 535 were exposed to both an atypical and conventional antipsychotic and 18 were exposed to sulpiride alone. The adjusted mortality HRs indicated no significant differences between those receiving conventional and atypical antipsychotics when people exposed to both were excluded (Model 1: adjusted HR 0.95, 95\% CI 0.87-1.03; Model 2: adjusted HR 0.94 , 95\% CI 0.86-1.03). In this analysis, sulpiride was included as a conventional antipsychotic, but there was also no significant difference if sulpiride was classified as an atypical one. Interestingly, people with dementia receiving atypical antipsychotics had a higher risk of acute cardiac events following drug exposure than those receiving conventional antipsychotics (PERR 3.3, 95\% CI 3.0-5.1), although the rates of pre-exposure were lower. Stroke risk was marginally lower in patients receiving atypical compared to conventional antipsychotics (PERR 0.82, 95\% CI 0.8-0.9).

When we examined mortality rates for 100-day blocks following the commencement of antipsychotic medication, the rate was highest in the first 100 days-11.5 (95\% CI 10.4-12.7) per 100 people per 100 days. This was a significantly higher rate than that for the 301- to 400-day block (8.7, 95\% CI 7.6-10.1). The rates for the intervening periods, namely 101-200 days and 201-300 days, were 9.4 (95\% CI 8.4-10.7) and 9.3 (95\% CI 8.2-10.5), respectively. 


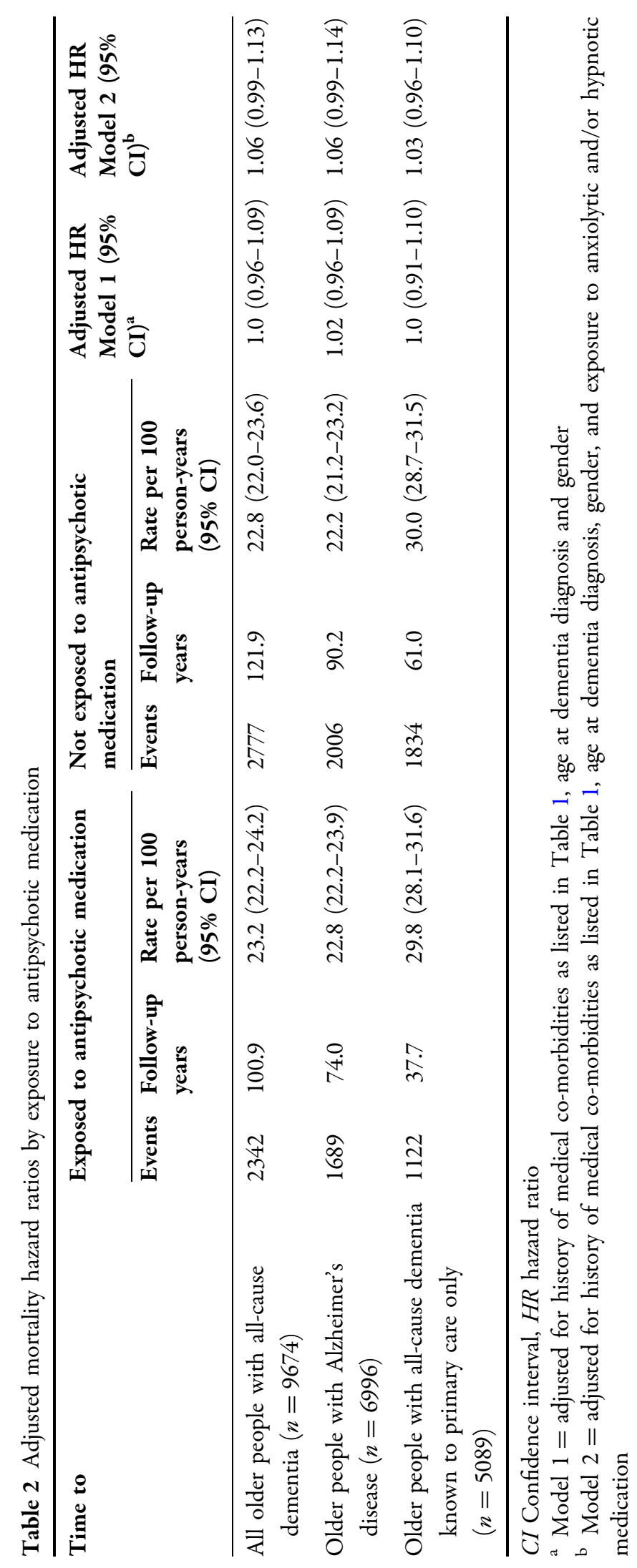


Table 3 Adverse event hazard ratio and adjusted prior event rate ratios by exposure to antipsychotic medication

\begin{tabular}{|c|c|c|c|c|}
\hline Adverse event & Exposed to antipsychotic & Not exposed to antipsychotic & Hazard ratio & PERR (95\% CI) \\
\hline \multicolumn{5}{|c|}{ Acute cardiac event } \\
\hline \multicolumn{5}{|c|}{ All-cause dementia } \\
\hline \multicolumn{5}{|l|}{ Before } \\
\hline$N$ per 1000 & $5.9(22 / 3721)$ & $7.1(42 / 5908)$ & 0.83 & \\
\hline $95 \% \mathrm{CI}$ & $3.9-9.0$ & $5.2-9.6$ & & \\
\hline \multicolumn{5}{|l|}{ After } \\
\hline$N$ per 1000 & $12.4(46 / 3720)$ & $15.1(89 / 5908)$ & 0.82 & $0.98(1.0-1.0)$ \\
\hline $95 \% \mathrm{CI}$ & $9.2-16.6$ & $12.2-18.6$ & & \\
\hline \multicolumn{5}{|l|}{ Alzheimer's } \\
\hline \multicolumn{5}{|l|}{ Before } \\
\hline$N$ per 1000 & $5.2(14 / 2690)$ & $9.6(41 / 4270)$ & 0.54 & \\
\hline $95 \% \mathrm{CI}$ & $3.1-8.8$ & $7.0-13.0$ & & \\
\hline \multicolumn{5}{|l|}{ After } \\
\hline$N$ per 1000 & $11.1(30 / 2680)$ & $12.4(53 / 4260)$ & 0.89 & $1.65^{*}(1.59-1.86)$ \\
\hline $95 \% \mathrm{CI}$ & $7.8-16.0$ & $9.5-16.2$ & & \\
\hline \multicolumn{5}{|c|}{ Known to primary care only } \\
\hline \multicolumn{5}{|l|}{ Before } \\
\hline$N$ per 1000 & $5.5(9 / 1642)$ & $8.5(29 / 3419)$ & 0.64 & \\
\hline $95 \% \mathrm{CI}$ & $2.9-10.5$ & $5.8-12.2$ & & \\
\hline \multicolumn{5}{|l|}{ After } \\
\hline$N$ per 1000 & $14.1(23 / 1634)$ & $12.9(44 / 3408)$ & 1.08 & $1.68^{*}(1.05-1.78)$ \\
\hline $5 \% \mathrm{CI}$ & $9.3-21.1$ & $9.6-17.3$ & & \\
\hline
\end{tabular}

Venous thromboembolism

All-cause dementia

Before

$\begin{array}{llll}N \text { per } 1000 & 6.4(24 / 3717) & 6.7(40 / 5909) & 0.96 \\ 95 \% \text { CI } & 4.3-9.6 & 5.0-9.2 & \end{array}$

After
$N$ per 1000
$13.0(48 / 3705)$
$6.9(41 / 5914)$
1.88
$1.95 *(1.83-2.0)$
95\% CI
9.8-17.2
$5.1-9.4$

Alzheimer's

Before

$\begin{array}{llll}N \text { per } 1000 & 7.0(19 / 2684) & 6.5(28 / 4276) & 1.0\end{array}$


Table 3 continued

\begin{tabular}{lllll}
\hline Adverse event & Exposed to antipsychotic & Not exposed to antipsychotic & Hazard ratio & PERR (95\% CI) \\
\hline $95 \%$ CI & $4.5-11.0$ & $5.0-9.2$ & & \\
After & & & & 1.8 \\
N per 1000 & $14.2(38 / 2674)$ & $7.7(33 / 4274)$ & $1.80^{*}(1.67-1.89)$ \\
$95 \%$ CI & $10.3-19.5$ & $5.4-10.8$ &
\end{tabular}

Known to primary care only

Before

$\begin{array}{llll}N \text { per } 1000 & 6.7(11 / 1639) & 9.6(33 / 3416) & 0.7 \\ 95 \% \text { CI } & 0.3-12.1 & 5.0-9.2 & \end{array}$

After

$\begin{array}{lllll}N \text { per } 1000 & 14.1(23 / 1632) & 7.6(26 / 3422) & 1.85 & 2.66^{*}(2.41-2.78) \\ 95 \% \text { CI } & 9.3-21.2 & 5.2-11.1 & & \end{array}$

\section{Stroke}

All-cause dementia

Before

\begin{tabular}{|c|c|c|}
\hline$N$ per 1000 & $35.0(128 / 3652)$ & $37.8(219 / 5789)$ \\
\hline $95 \% \mathrm{CI}$ & $29.4-41.6$ & $33.1-43.1$ \\
\hline
\end{tabular}

After

$\begin{array}{lll}N \text { per } 1000 & 65.8(236 / 3587) & 50.8(292 / 5749) \\ 95 \% \text { CI } & 57.9-74.7 & 45.2-57.0\end{array}$

Alzheimer's

Before

\begin{tabular}{|c|c|c|}
\hline$N$ per 1000 & $25.6(68 / 2653)$ & $34.0(143 / 4207)$ \\
\hline $95 \% \mathrm{CI}$ & $20.2-32.4$ & $28.8-40.0$ \\
\hline
\end{tabular}

After

$\begin{array}{lllll}N \text { per } 1000 & 61.1(159 / 2601) & 39.6(166 / 4190) & 1.54 & 2.06^{*}(1.97-2.13) \\ 95 \% \text { CI } & 52.3-71.4 & 34.0-46.1 & & \end{array}$

Known to primary care only

Before

$\begin{array}{llll}N \text { per } 1000 & 41.9(67 / 1599) & 50.2(167 / 3327) & 0.83 \\ 95 \% \text { CI } & 32.9-53.2 & 43.1-58.4\end{array}$

After 
Table 3 continued

\begin{tabular}{clllr}
\hline Adverse event & Exposed to antipsychotic & Not exposed to antipsychotic & Hazard ratio & PERR (95\% CI) \\
\hline$N$ per 1000 & $70.2(111 / 1581)$ & $48.6(162 / 3330)$ & 1.44 & $1.73^{*}(1.66-1.75)$ \\
$95 \% \mathrm{CI}$ & $58.2-84.5$ & $41.7-56.7$ & &
\end{tabular}

\section{Hip fracture}

All-cause dementia

Before

\begin{tabular}{|c|c|c|c|c|}
\hline$N$ per 1000 & $24.4(90 / 3679)$ & $24.5(143 / 5842)$ & 1.0 & \\
\hline $95 \% \mathrm{CI}$ & $19.9-30.1$ & $20.8-28.8$ & & \\
\hline \multicolumn{5}{|l|}{ After } \\
\hline$N$ per 1000 & $55(200 / 3617)$ & $34.2(199 / 5817)$ & 1.61 & $1.62^{*}(1.59-1.65)$ \\
\hline $95 \% \mathrm{CI}$ & $47.9-63.2$ & $29.8-39.3$ & & \\
\hline
\end{tabular}

Alzheimer's

Before

\begin{tabular}{|c|c|c|c|c|}
\hline$N$ per 1000 & $27.1(72 / 2653)$ & $25.3(107 / 4226)$ & 1.07 & \\
\hline $95 \% \mathrm{CI}$ & $21.5-34.2$ & $20.9-30.6$ & & \\
\hline \multicolumn{5}{|l|}{ After } \\
\hline$N$ per 1000 & $59.0(154 / 2608)$ & $33.4(141 / 4213)$ & 1.76 & $1.65^{*}(1.61-1.71)$ \\
\hline $95 \% \mathrm{CI}$ & $50.4-69.1$ & $28.3-39.4$ & & \\
\hline
\end{tabular}

Known to primary care only

Before

\begin{tabular}{llll}
$N$ per 1000 & $25.2(41 / 1623)$ & $22.4(76 / 3390)$ & 1.13 \\
$95 \%$ CI & $18.5-34.3$ & $17.9-28.1$ & \\
After & & & 1.76 \\
$N$ per 1000 & $57.1(91 / 1593)$ & $32.3(109 / 3369)$ & $1.57^{*}(1.52-1.65)$ \\
$95 \%$ CI & $46.5-70.1$ & $26.8-39.0$ & \\
\hline
\end{tabular}

* Significantly higher likelihood of acute cardiac event, venous thromboembolism, stroke and hip fracture in those receiving antipsychotic medication

PERR Prior event rate ratio

\section{Sensitivity Analyses}

When we excluded patients with a known contact with secondary care specialist mental health services for older people (outpatient and community team), the main cohort was reduced substantially from 9674 to 5089 people with dementia. Adjusted mortality HRs 
(both Model 1 and 2) showed no differences between those exposed and not exposed to antipsychotic medication (Table 2). The PERR analysis showed a raised risk of acute cardiac event, venous thromboembolism, stroke and hip fracture for people with dementia receiving antipsychotics compared to non-exposed patients (Table 3).

When we included people with cancer within 1 year of death in the dementia cohort, the adjusted mortality HR was still non-significant (Model 1: HR 0.97, 95\% CI 0.92-1.02).

\section{DISCUSSION}

\section{Summary of Main Findings}

The most important finding in our study was the increased likelihood of venous thromboembolism, stroke and hip fracture in older people living with dementia who were exposed to antipsychotic medication. The findings for people living with $\mathrm{AD}$ mirrored those for people living all-cause dementia, but the former had an additional increased risk of an acute cardiac event.

Surprisingly, there was no overall increased risk of death for older people living with dementia exposed to antipsychotic medication compared to non-exposed individuals although the mortality was comparatively high during the first 100 days of treatment with an antipsychotic and subsided thereafter. The absence of increased long-term mortality risk needs to be viewed with caution in view of a number of methodological limitations outlined below, including the absence of data on the duration of treatment. Interestingly, there was no difference in the risk of death between people receiving atypical and conventional antipsychotics.

The main study was conducted on 9674 older people (aged 65 years and over) with dementia in the region of Wales in the UK; this would include people living in their own homes as well as in residential and nursing homes.

\section{Results in Context}

Our finding of a comparatively high mortality in the first 100 days after the initiation of antipsychotic treatment in older people with dementia is consistent with the body of literature describing the short-term increased mortality associated with antipsychotic use in dementia [11, 12, 33]. However, the absence of any overall long-term increased risk of mortality associated with exposure to antipsychotic medication requires a more detailed consideration. The first factor is that other studies which have examined longer-term effects of antipsychotics have similarly found no increased risk [22, 23]; in particular, Lopez et al. [22] showed that it was the presence of BPSD that was associated with the increased risk of mortality. Secondly, our cohort study occurred later than previously published studies, and most of the cohort period is after the publication of the CSM [9] and FDA [10] guidances; this may have resulted in more careful prescribing [34, 35], although the rates of ischaemic heart disease were similar in both exposed and non-exposed groups. Thirdly, our cohort has a relatively high mean age and is population based rather than a selected sample as utilised for some other cohort studies $[12,19]$. Additionally, we have high rates of medical co-morbidity-almost double the rate of pre-existing cerebrovascular and significant cardiac disease compared to a large Canadian 
cohort study [33]. Clearly many of our cohort members would not have satisfied the stringent selection criteria for recruitment into a RCT for the treatment of BPSD in dementia. Also there may be a survival effect, as well as the possible role of improved aftercare compared to previous studies; there are comprehensive community services in Wales (UK) for older people with dementia, including in-reach to care homes [36]. One further explanation for a lack of overall increased mortality associated with antipsychotic use derives from studies that include measures of psychotic symptoms and agitation-when controlling for these factors the risk of mortality was not increased [20, 22], and this could be accounted for by the use of restraint in people not receiving medication [20]. However, there are also a number of methodological limitations that could account for the absence of increased long-term mortality associated with antipsychotics. In particular, the lack of duration of treatment with antipsychotics is an important consideration, as some people may have received a short-term prescription only. This could well be the case for an episode of delirium in the context of dementia. The finding that mortality was relatively high in the first 100 days following initiation of treatment and then subsided could be explained by a short duration of treatment. Secondly, stratification into groups of exposed and non-exposed to antipsychotic medication, respectively, for the Cox's proportional hazard mortality analysis occurred following the diagnosis of dementia and was not time dependent (unlike for the PERR adjustment method); consequently, some people living with dementia for that particular analysis may be included in the exposed group despite having a significant period of non-exposure.

Besides examining mortality, other research into adverse outcomes in antipsychotic use in older people with dementia has focused on falls and stroke [13, 37]. Our findings of both an increased risk of hip fracture and stroke are consistent with the results of these previous studies. Our study utilised both hospital discharge data and primary care records to identify cerebrovascular adverse events, reducing the likelihood of more minor events in the community (such as transient ischaemic attack) or more terminal events managed in a care home setting being missed.

The risk of acute cardiac events as a consequence of antipsychotic use in older people with dementia has not been previously examined in detail $[5,6,8]$, but there is an expectation of increased in risk based on drug trial data and the findings of electrocardiogram abnormalities in younger populations [38]. We had high levels of pre-existing ischaemic heart disease in our dementia cohort and found an increased risk of acute cardiac event in people living with $\mathrm{AD}$ who were exposed to antipsychotics, those living with dementia who received antipsychotics and were known only to primary care and those receiving atypical antipsychotic drugs compared to those receiving conventional ones. However, events were relatively few compared to other outcomes, in particular pre-treatment in those exposed to antipsychotic medication (especially atypicals). The higher risk associated with atypical compared to conventional antipsychotic medication may be explained by clinicians selecting one drug over another in 'at risk' patients; when prior events influence the probability of drug use, then bias may occur when using the PERR method [30].

An increased risk of venous thromboembolism associated with antipsychotic medication has previously been reported in an UK population-based nested case-control study, with older people at 
particular risk [39], and also in older people with dementia in a German nested case-control study [40]. Our study supports this finding in older people with dementia; inactivity-related venous stasis may not be the only mechanism involved-enhanced platelet aggregation and raised anticardiolipin antibodies may also be important factors [41].

Conventional antipsychotic agents have generally been found to be associated with a greater risk of mortality compared to newer atypical drugs [12, 17-19, 33, 42-45], but there are some exceptions $[20,22]$. We found no difference between conventional and atypical antipsychotic drugs for mortality or any other adverse outcomes regardless of how sulpiride was categorised. This could be explained by some of the reasons previously outlined; in particular, the fact that our cohort is more recent. Studies based on Medicare and Medicaid primarily compared atypical drugs with haloperidol; the latter had often been prescribed in relatively high dosages for this frail client group $[18,42]$. Other studies have failed to adequately consider the potential confounding effect of prescribing relatively high-dose typical antipsychotics for patients receiving palliative cancer care [19, 33, 43].

\section{Strengths and Limitations}

This is the first large, long-term UK population based study of adverse outcomes associated with exposure to antipsychotics in older people with dementia. In utilising the SAIL databank we were able to assess baseline co-morbidity and identify adverse outcomes from both hospital in-patient episodes and primary care records, thereby reducing the possibility of missing adverse events. Additionally, we are able to include all dementia subtypes and not restrict our study to AD. Although the detection of dementia rate in
Wales in 2015 was $43.4 \%$, this estimated rate is based on figures utilising the basic Read codes used in the NHS QOF data [46]. Our study pre-dates the use of these codes for QOF in Wales, and one of the strengths of the study is the broader use of diagnostic codes to identify dementia. The dementia Read codes used in our study are similar to those used in research based upon the Clinical Practice Research Datalink in England; they have been found to have positive predictive value of $80-90 \%$ [47] and have high levels of agreement with Hospital Episode Statistics data [48]. Our case identification is therefore sufficiently reliable for a study of this nature, particularly as we were primarily interested in the effects of antipsychotic prescribing in patients known to have dementia in the primary care setting. Additionally, our cohort is generally from a later period than comparable studies-2003-2011 and predominantly after publication of the CSM and FDA guidances. Other strengths are our broad use of diagnostic codes, ability to control for effects of other psychotropic use and our careful exclusion criteria. Older people with pre-existing dementia are particularly vulnerable to experiencing concurrent delirium when physically unwell, and the lack of data on co-morbid delirium could be relevant for the Cox's mortality HR analyses. Unfortunately, delirium is poorly recorded in general practice [49], and so it is difficult to control for this factor. However, we chose the adjusted PERR method for non-fatal adverse outcomes as it can reduce bias as a consequence of unmeasured confounding [30, 50]. Additionally, as we were examining antipsychotic prescribing in general practice and subsequent serious adverse outcomes in relation to conditions that frequently lead to hospitalisation, it is unlikely that co-morbid delirium at the time of index prescribing significantly influenced our findings. 
There are limitations to the data available within the SAIL databank, namely the lack of information on individual drug frequency and the duration of prescription. The influence of these two factors has been discussed previously, as well as the limitations of the Cox proportional hazard analysis for mortality risk. Another deficiency is the absence of prescribing data for secondary care. However, in our sensitivity analyses we excluded patients known to older peoples' mental health services, and the findings remained relatively consistent. There remains the possibility that a small number of people may have had a hospital in-patient episode when they were exposed to an antipsychotic for a short period, and this was not continued on discharge from hospital, or an antipsychotic could have been prescribed for BPSD before the dementia diagnosis was formally noted in the patient's records. Another limitation associated with the use of linked routine data is the inability to consider the influence of degree of functional and cognitive impairment or the presence and severity of BPSD.

\section{CONCLUSION}

Although there are only limited effects on behavioural and psychological symptoms with antipsychotic medications in older people with dementia, they continue to be used despite concerns over their safety [5]. Guidelines stress the importance of managing contributing medical co-morbidity, as well as the use of environmental, psychological and behavioural treatment strategies [2]. Although evidence for non-pharmacological interventions is increasing [51, 52], the availability and implementation of these interventions remain restricted by resources, and additionally the evidence for their efficacy still requires further evaluation [18].

Our study shows that there is a clear increased risk of adverse medical outcomes, in particular venous thromboembolism (DVT and $\mathrm{PE})$, stroke and hip fracture in older people living with dementia who are exposed to antipsychotic medications. This risk supports recommendations restricting non-emergency antipsychotic medication use in people with dementia to those with psychosis or severe aggression when other non-pharmacological treatment strategies have failed [52-54].

\section{ACKNOWLEDGEMENTS}

This study and the article processing charges were funded by grants from Abertawe Bro Morgannwg University Health Board and the Farr Institute. The Farr Institute is supported by a consortium of ten UK research organisations: Arthritis Research UK, the British Heart Foundation, Cancer Research UK, the Economic and Social Research Council, the Engineering and Physical Sciences Research Council, the Medical Research Council, the National Institute of Health Research, the National Institute for Social Care and Health Research (Welsh Government) and the Chief Scientist Office (Scottish Government Health Directorates). MRC Grant No: MR/K006525/1. All named authors meet the International Committee of Medical Journal Editors (ICMJE) criteria for authorship for this manuscript, take responsibility for the integrity of the work as a whole, and have given final approval for the version to be published.

Disclosures. Michael Dennis, Laura Shine, Ann John, Amanda Marchant, Joanna McGregor, Ronan A. Lyons and Sinead Brophy confirm that they have no conflicts of interest. 
Compliance with Ethical Standards. This article does not contain any new studies with human or animal subjects performed by any of the authors. Ethical approval was granted from the HIRU Information Governance Review Panel (IGRP), an independent body consisting of a range of government, regulatory and professional agencies, which oversees study approvals in line with permissions already granted to the analysis of data in the SAIL databank [24, 25]. For this type of study individual formal consent was not required. The results are reported in accordance with the STROBE checklist (http://www.epidem.com/).

Data Availability. Data are stored within the Secure Anonymised Information Linkage (SAIL) databank at the Health Information Research Unit (HIRU) at Swansea University. All proposals to use SAIL datasets must comply with HIRU's information governance policy. Applications to use the data available in the SAIL Databank and processes to become an approved user can be made through http:// www.saildatabank.com.

Open Access. This article is distributed under the terms of the Creative Commons Attribution 4.0 International License (http:// creativecommons.org/licenses/by/4.0/), which permits unrestricted use, distribution, and reproduction in any medium, provided you give appropriate credit to the original author(s) and the source, provide a link to the Creative Commons license, and indicate if changes were made.

\section{APPENDIX 1}

See Table 4.
Table 4 Read codes for dementia

Senile dementia

E00..

Senile/pre-senile dementia

E00..

Uncomplicated senile dementia

E000.

Pre-senile dementia

E001.

Uncomplicated pre-senile dementia

E0010

Pre-senile dementia with delirium

E0011

Pre-senile dementia with paranoia

E0012

Pre-senile dementia with depression

E0013

Pre-senile dementia NOS

E001z

Senile dementia with depressive or paranoid

E002. features

Senile dementia with paranoia

E0020

Senile dementia with depression

E0021

Senile dementia with depressive or paranoid

$\mathrm{E} 002 \mathrm{z}$ features

Senile dementia with delirium

E003.

Arteriosclerotic dementia

E004.

Multi-infarct dementia

E004.

Uncomplicated arteriosclerotic dementia

E0040

Arteriosclerotic dementia with delirium

E0041

Arteriosclerotic dementia with paranoia

E0042

Arteriosclerotic dementia with depression

E0043

Arteriosclerotic dementia NOS

E004z

Other alcoholic dementia

E012.

Chronic alcoholic brain syndrome

E0120

Dementia in conditions EC

E041.

[X]Dementia in Alzheimer's disease

Eu00.

[X]Dementia in Alzheimer's disease with early

$\mathrm{Eu} 000$ onset

[X]Pre-senile dementia, Alzheimer's type $\mathrm{Eu000}$

$[\mathrm{X}]$ Primary degenerative dementia, Alzheimer's

$\mathrm{Eu} 000$ type, pre-senile onset

$[\mathrm{X}]$ Dementia in Alzheimer's disease with late Eu001 
Table 4 continued

[X]Primary degenerative dementia of Alzheimer's Eu001

type, senile onset

$[\mathrm{X}]$ Senile dementia, Alzheimer's type

Eu001

[X]Dementia in Alzheimer's disease, atypical or mixed type

$[\mathrm{X}]$ Alzheimer's dementia unspecified

$\mathrm{Eu} 00 \mathrm{z}$

$[\mathrm{X}]$ Dementia in Alzheimer's disease, unspecified

$\mathrm{EuO0z}$

$[\mathrm{X}]$ Arteriosclerotic dementia

Eu01.

[X]Vascular dementia

Eu01.

$[\mathrm{X}]$ Vascular dementia of acute onset

$\mathrm{Eu} 010$

[X]Multi-infarct dementia

$[\mathrm{X}]$ Predominantly cortical dementia

$[\mathrm{X}]$ Sub-cortical vascular dementia

$[\mathrm{X}]$ Mixed cortical and sub-cortical vascular dementia

$[\mathrm{X}]$ Other vascular dementia

$[\mathrm{X}]$ Vascular dementia, unspecified

$[\mathrm{X}]$ Dementia in other diseases classified elsewhere

$[\mathrm{X}]$ Dementia in Picks disease

$[\mathrm{X}]$ Dementia in Creutzfeldt-Jacob disease

$[\mathrm{X}]$ Dementia in Huntington's disease

$[\mathrm{X}]$ dementia in Parkinson's disease

$[\mathrm{X}]$ dementia in HIV disease (this may be a sensitive code)

$[\mathrm{X}]$ Lewy body dementia

Eu025

$[\mathrm{X}]$ Dementia in other specified diseases classified Eu02y elsewhere

[X]Primary degenerative dementia NOS

$\mathrm{Eu} 02 \mathrm{z}$

[X]Senile dementia NOS

$\mathrm{Eu} 02 \mathrm{z}$

[X]Senile dementia, depressed or paranoid type

$\mathrm{Eu} 02 \mathrm{z}$

$[\mathrm{X}]$ Unspecified dementia

$\mathrm{Eu} 02 \mathrm{z}$

$[\mathrm{X}]$ Delirium superimposed on dementia

Eu041

Alzheimer's disease

F110.

Alzheimer's disease with early onset

F1100
Table 4 continued

Alzheimer's disease with late onset

F1101

Pick's disease

F111.

Senile degeneration of brain

F112.

Lewy body disease

F116.

Cerebral degeneration in other disease

F11x

Cerebral degeneration due to alcohol

F11x0

Cerebral degeneration due to beriberi

F11x1

Cerebral degeneration due to cerebrovascular

F11x2 disease

Cerebral degeneration due to myxodema

F11x5

Cerebral degeneration due to Vitamin B12

F11x6 deficiency

Cerebral degeneration due to Jacob-Creutzfeldt

F11x7 disease

Cerebral degeneration due to multifocal

F11x8 leucoencephalopathy

Cerebral degeneration due to Parkinson's disease F11x9

Cerebral degeneration due to other disease NOS F11xz

$[\mathrm{X}]$ Other Alzheimer's disease

Fyu30

\section{REFERENCES}

1. Department of Health. Living well with dementia: a national dementia strategy. 2009. https://www.gov. uk/government/uploads/system/uploads/attachme nt_data/file/168220/dh_094051.pdf. Accessed 3 Sep 2014.

2. National Institute for Health and Clinical Excellence-Social Care Institute for Excellence (NICE-SCIE). Dementia: the NICE-SCIE guideline on supporting people with dementia and their carers in health and social care (updated). National clinical practice guideline 42. London: The British Psychological Society and the Royal College of Psychiatrists; 2011.

3. Maher AR, Maglione M, Bagley S, Suttorp M, Hu JH, Ewing B, Wang Z, Timmer M, Sultzer D, Shekelle PG. Efficacy and comparative effectiveness of atypical antipsychotic medications for off-label uses in adults: a systematic review and meta-analysis. JAMA. 2011;306:1359-69. 
4. Lee P, Gill S, Freedman M, Bronskill S, Hillmer M, Rochan P. Atypical antipsychotic drugs in the treatment of behavioural and psychological symptoms of dementia: systematic review. BMJ. 2004;329:75-8.

5. Ballard C, Howard R. Neuroleptic drugs in dementia: benefits and harm. Nat Rev Neurosci. 2006;7:492-500.

6. Schneider LS, Dagerman K, Insel PS. Efficacy and adverse effects of atypical antipsychotics for dementia: meta-analysis of randomized, placebo-controlled trials. Am J Geriatr Psychiatry. 2006;14:191-210.

7. Ballard CG, Gautheir S, Cummings JL, Brodaty H, Grossberg GT, Robert P, Lyketsos CG. Management of agitation and aggression associated with Alzheimer disease. Nat Rev Neurol. 2009;5:245-55.

8. Ballard CG, Waite J, Birks J. Atypical antipsychotics for aggression and psychosis in Alzheimer's disease. Cochrane Database Syst Rev 2006;(1):CD003476.

9. Committee on Safety of Medicines. Atypical antipsychotic drugs and stroke: message from Professor Gordon Duff, chairman, (CEM/CMO/ 2004/1). London: Committee on Safety of Medicines; 2004.

10. Federal Drug Administration Public Health Advisory. Death with antipsychotics in elderly patients with behavioral disturbances. 2010. www. fda.gov/drugs/drugsafety/. Accessed 3 Sep 2014.

11. Schneider L, Dagerman K, Insel P. Risk of death with atypical antipsychotic drug treatment for dementia: meta-analysis of randomized placebo-controlled trials. JAMA. 2005;294:1934-43.

12. Rochon $\mathrm{P}$, Normand S, Gomes T, Gill S, Anderson G, Melo M, Sykora K, Lipscombe L, Bell C, Gurwitz $\mathrm{J}$. Antipsychotic therapy and short-term serious events in older adults with dementia. Arch Intern Med. 2008;2008(168):676-83.

13. Banerjee $\mathrm{S}$. The use of antipsychotic medication for people with dementia: time for action. London: Department of Health; 2009.

14. National Audit Office. Improving services and support for people with dementia. London: The Stationery Office; 2007.

15. Crugel M, Paton G, Singh P, Jeboda R, Treloar A. Antipsychotics in people with dementia: frequency of use and rationale for prescribing in a UK mental health service. Psychiatrist. 2012;36:165-9.

16. Barnes T, Banerjee S, Collins N, Treloar A, McIntyre $\mathrm{S}$, Paton C. Antipsychotics in dementia: prevalence and quality of antipsychotic drug prescribing in UK mental health services. $\mathrm{Br} \mathrm{J}$ Psychiatry. 2012;201:221-6.

17. Kales H, Kim H, Zivin K, Valenstein M, Seyfried L, Chiang C, Cunningham F, Schneider L, Blow F. Risk of mortality among individual antipsychotics in patients with dementia. Am J Psychiatry. 2012;169:71-9.

18. Huybrechts K, Gerhard T, Crystal S, Olfson M, Avorn J, Levin R, Lucas J, Schneeweiss S. Differential risk of death in older residents in nursing homes prescribed specific antipsychotic drugs: population-based cohort study. BMJ. 2012;344:e977.

19. Musicco M, Palmer K, Russo A, Caltagirone C, Adorni F, Pettenati C, Bisanti L. Association between prescription of conventional or atypical antipsychotic drugs and mortality in older persons with Alzheimer's disease. Dement Geriatr Cogn Disord. 2011;31:218-24.

20. Raivio MM, Laurila JV, Strandberg TE, Tilvis RS, Pitkälä KH. Neither atypical nor conventional antipsychotics increase mortality or hospital admissions among elderly patients with dementia: a 2-year prospective study. Am J Geriatr Psychiatry. 2007;15:416-24.

21. Simoni-Wastila L, Ryder PT, Qian J, Zuckerman IH, Shaffer T, Zhao L. Association of antipsychotic use with hospital events and mortality among medicare beneficiaries residing in long-term care facilities. Am J Geriatr Psychiatry. 2009;17:417-27.

22. Lopez OL, Becker JT, Chang Y-F, Sweet RA, Aizenstein H, Snitz B, Saxton J, McDade E, Kamboh MI, DeKosky ST, Reynolds CF III, Klunk WE. The long-term effects of conventional and atypical antipsychotics in patients with probable Alzheimer's disease. Am J Psychiatry. 2013;170:1051-8.

23. Sultana J, Chang C, Hayes R, Broadbent M, Stewart $\mathrm{R}$, Corbett A, Ballard C. Associations between risk of mortality and atypical antipsychotic use in vascular dementia: a clinical cohort study. Int J Geriatr Psychiatry. 2014;29(12):12049-542.

24. Ford DV, Jones KH, Verplancke J-P, Lyons RA, John G, Brown G, Brooks C, Bodger O, Couch T, Leake K. The SAIL Databank: building a national architecture for e-health research and evaluation. BMC Health Serv Res. 2009;9:157.

25. Lyons RA, Jones KH, John G, Brooks CJ, Verplancke J-P, Ford DV, Brown G, Leake K. The SAIL databank: linking multiple health and social care datasets. BMC Med Inform Decis Mak. 2009;9:3-25. 
26. Jones KH, Ford DV, Jones C, D'Silva R, Thompson S, Brooks CJ, Heaven ML, Thayer DS, McNerney CL, Lyons RA. A case study of the Secure Anonymous Information Linkage (SAIL) Gateway: a privacy protecting remote access system for health related research and evaluation. J Biomed Inform 2014;50:196-204.

27. QOF READ codes v27 for 2013/2014. http://www. pcc-cic.org.uk/article/qof-read-codes-v28. Accessed 28 Feb 2014.

28. Khan N, Perera R, Harper S, Rose P. Adaption and validation of the Charlson Index for READ/OXMIS coded database. BMC Family Pract 2010;11;1. http://www.biomedcentral.com/1471-2296/11/1.

29. Bottle A, Aylin P. Comorbidity scores for administrative data benefited from adaption to local coding and diagnostic practices. J Clin Epidemiol. 2011;64:1426-33.

30. Uddin $M$, Groenwold R, van Staa $T$, de Boer A, Belitse S, Hoes A, et al. Performance of prior event rate ration adjustment method in pharmacoepidemiology: a stimulation study. Pharmacoepidemiol Drug Saf. 2015;24:468-77.

31. Brophy S, Jones K, Rahman M, Zhou S-M, John A, Atkinson $\mathrm{M}$, et al. Incidence of Campylobacter and Salmonella infections following first prescription for PPI: a cohort study using routine data. Am J Gastroenterol. 2013;108:1094-100.

32. Stata version 12. 2011. http://www.stata.com.

33. Gill S, Bronskill S, Normand S-LT, Anderson G, Sykora K, Lam K, et al. Antipsychotic drug use and mortality in older adults with dementia. Ann Intern Med. 2007;146:775-86.

34. Health and Social Care Information Centre. National Dementia \& Antipsychotic Prescribing Audit 2012. HSCIC, 2012.

35. Barber R, Donaldson T. Antipsychotic medication in Dementia-United Kingdom perspective. IPA Bulletin, International Psychogeriatric Association, June 8-10, 2010.

36. Colgate R, Davies $\mathrm{K}$, Lambert $\mathrm{H}$, Turner A. Controlling the confusion: using barrier analysis in the care home sector. Adv Psychiatr Treat. 2012;18:426-33.

37. Kleijer BC, van Marum RJ, Egberts AC, Jansen PA, Knol W, Heerdink ER. Risk of cerebrovascular events in elderly users of antipsychotics. J Psychopharmacol. 2009;23:909-14.

38. Reilly J, Ayis S, Ferrier I, Jones S, Thomas S. QTc interval abnormalities and psychotropic drug therapy in psychiatric patients. Lancet. 2000;355:1048-52.

39. Parker C, Coupland C, Hippisley-Cox J. Antipsychotic drugs and risks of venous thromboembolism: nested case-control study. BMJ. 2010;341:c4245.

40. Schmedt N, Garbe E. Antipsychotic drug use and the risk of venous thromboembolism in elderly patients with dementia. J Clin Psychopharmacol. 2013;33:753-8.

41. Hagg S, Spigset O. Antipsychotic induced venous thromboembolism. CNS Drugs. 2002;16:765-76.

42. Gerhard T, Huybrechts K, Olfson M, Schneeweiss S, Bobo W, Doraiswamy $\mathrm{P}$, et al. Comparative mortality risks of antipsychotic medications in community-dwelling older adults. Br J Psychiatry. 2014;205:44-51.

43. Liperoti R, Onder G, Landi F, Lapane K, Mor V, Bernabei R, Gambassi G. All-cause mortality associated with atypical and conventional antipsychotics among nursing home residents with dementia: a retrospective cohort study. J Clin Psychiatry. 2009;70:1340-7.

44. Jackson J, Schneeweiss S, VanderWeele T, Blacker D. Quantifying the role of adverse events in the mortality difference between first and second-generation antipsychotics in older adults: systematic review and meta-synthesis. PLoS One. 2014;9(8):e105376. doi:10.1371/journal.pone. 0105376 .

45. Trifiro G, Sultana J, Spina E. Are the safety profiles of antipsychotic drugs used in dementia the same? An updated review of observational studies. Drug Saf. 2014;37(7):501-20.

46. Alzheimer's Society. Wales dementia diagnosis rates 2015. https://www.alzheimers.org.uk/site/scripts/ download_info.php?fileID=2797. Accessed 24 Nov 2016.

47. Khan N, Harrison S, Rose P. Validity of diagnostic coding within the General Practice Research Database: a systematic review. Br J Gen Pract. 2010;60:128-36.

48. Brown A, Kirichek O, Balkwill A, Reeves G, Beal V, Sudlow C, Gallacher J, Green J. Comparison of dementia recorded in routinely collected hospital admission data in England with dementia recorded in primary care. Emerg Themes Epidemiol. 2016;13:11. doi:10.1186/s12982-0160053-z.

49. Young J, Inouye S. Delirium in older people. BMJ. 2007;334:842-6. 
50. Othman F, Crooks C, Card T. Community acquired pneumonia incidence before and after proton pump inhibitor prescription: a population based study. BMJ. 2016;355:i5813. doi:10.1136/bmj.i5813.

51. Livingston G, Kelly L, Lewis-Holmes E, Baio G, Morris S, Patel N, et al. Non-pharmacological interventions for agitation in dementia: a systematic review of randomised controlled trials. Br J Psychiatry. 2014;205:436-42.

52. Kales H, Gitlin L, Lyketsos C. Assessment and management of behavioural and psychological symptoms in dementia. BMJ. 2015;350:h369.
53. Corbett A, Burns A, Ballard C. Don't use antipsychotics routinely to treat agitation and aggression in people with dementia. BMJ. 2014;349:g6420.

54. American Psychiatric Association. Guideline on the use of antipsychotics to treat agitation or psychosis in patients with dementia. 2016. http:// psychiatryonline.org/doi/pdf/10.1176/appi.books. 9780890426807. Accessed 8 June 2016. 